\title{
Programme and Financial Management of JSY Scheme under NRHM: a Qualitative Study in Three South Indian States
}

\author{
Dr. D.C. Nanjunda \\ Centre for the Study of Social Exclusion and Inclusive Policy, Mysore University, Mysore-06. \\ Email: ajdmeditor@yahoo.co.in
}

\begin{abstract}
Maternal mortality in rural parts is a burning issue today. Janani Suraksha Yojana (JSY) is a safe and secured motherhood intervention under the National Rural Health Mission (NRHM) being implemented with the objective of reducing maternal and neo-natal mortality by promoting and increasing institutional delivery among the poor pregnant women in the rural parts of the country. Janani Suraksha Yojana (JSY) is a safe motherhood intervention under the National Rural Health Mission (NHM).it is implemented all over the country since 2005. JSY is basically a conditional cash transfer benefit scheme. It is a $100 \%$ central government supported scheme and ministry of health and family welfare will channelize the fund to the all state health societies. This study has been conducted in there south Indian states focusing programme and financial management of the JSY scheme and to find out any lacunas in the delivery system.
\end{abstract}

Keywords: Janani Suraksha Yojana (JSY), National Rural Health Mission (NRHM), financial management, delivery system

\section{Background}

The Janani Suraksha Yojna (JSY) is a government of India's' vital scheme for speedily decreasing maternal and infant mortality rates with a specific focus on escalating institutional and safe deliveries for the families belongs to the below poverty line (BPL) category in the country. JSY is a part of National Rural Health Mission (NRHM) covering all pregnant women who belong to the true BPL group, are over 19 years of age or those who have had two live births. Actually JSY was launched in the year 2003 was likely to modify the current National Maternity Benefit scheme which provides improved diet for the pregnant women below the poverty line (Mavalankar, 2009). Apart from supplying a healthy diet plan for pregnant women, the JSY actually provides antenatal care and help in the form of cash during pregnancy stage. Next, this system focuses on the poor women who would usually be short of cash and it is guaranteed that the money support given in this scheme is made accessible to her in shortest possible time easily. Further, execution of Janani Suraksha Yojana (JSY) has shown merely prominent advancement with number of women benefiting out of it slowly growing significantly over the last few years in the country. This evaluation study has been conducted in three south Indian states with the funding support from the Indian Council of Medical Research (Govt. of India).

\section{Objective and Methodology}

The major objective is to find out Programme and Financial Management of the JSY Scheme under NRHM. This study has been conducted in the selected districts in Karnataka, Tamil nadu Andra Pradesh (undivided) states of south India. Around 43 different stake holders from the 9 districts have been interviewed with a survey questioner. Study done during 2015-2-17 with ICMR grants. Data has been analyzed using SPSS software 


\section{Result and Discussion}

Normally all schemes would have certain elements. All these elements will play a key role and coordination among these elements will be very vital. In this issue, some of the vital components of the JSY programme including planning for JSY activities, estimation, infrastructure requirement, fund flow mechanism, accreditation of private hospitals, community mobilization activities, monitoring etc have been discussed here in detail.

\section{Planning for JSY activities:}

The District health society or the District NRHM society is the major agency for the planning and implementation of the JSY programme in any District. They are bounded to prepare an annual implementation plan for the whole district including required budget, supervision and valuation of progress of scheme etc. The district health society will guide and supervise the personnel activity involved in the execution of the programme. The health society prepares an annual plan starting from the sub-centre (if any) till the next higher level. The District health society needs to collect, compile and consolidate the accepted number of institutional deliveries for the year for the entire District. Normally estimation will be done based on --

a) Estimation of the total deliveries taking place and the birth rate into consideration;

b) Institutional deliveries took place in the previous year's especially after the introduction of the JSY programme;

c) By super imposing the trend on the augment over the quarters in the preceding years.

In Tamil nadu and Andhra Pradesh the officials follow two types of methods to estimate the demand under JSY. The first type is based on the number of expected pregnancies in a year and the second is based on the number of institutional deliveries both at the private and government hospitals in the preceding years. This information will be calculated based on the information provided by the various services providers including the sub-centers, $\mathrm{PHCs}, \mathrm{CHCs}$ and the district level. In some occasion usually they merge all the estimated plans received from the lower end (SC/PHCs/CHCs) and therefore consolidate at the district level. In this issue the finally approved plan will undergo rigors securitization in the meeting comprising the medical officers of PHC, CHC, District health officials and the NRHM society.

During the plan stage one more sub plan would be prepared for additional manpower equipment, drugs and operation theaters to meet the unexpected demand of the institutional deliveries. In this issue the state nodal officers, PHC, CHC medical officers and the local ANM's will be actively participated in the preparation of the plan. The state office will normally set the target for the each district. While estimating the District NRHM society will take proportion of the hospital deliveries in the preceding years for consideration to set their target for institutional deliveries for the coming year. Generally around 10 to $15 \%$ will be added to the state target while preparing the plan for the next year at the each district level. The plan will also provide provision to meet any unexpected events during the course of the execution. Members involving in the preparation of the plan will be given required training or support through the state health resource research centers or from the District training centers.

\section{Empanelment of the Accredited Private Institutions:}

As per the government of India rule, JSY can be implemented even in the selected private hospitals. Only those hospitals which have proven records of handing deliveries and having required advanced medical facilities will be listed by the district health authority to implement the JSY scheme. Private hospitals have been activity engaged in all three States to increase institutional deliveries under the JSY scheme. In majority cases this private accredited hospitals have been located in the urban areas only. In Tamil Nadu around 17 private hospitals have been short listed in the studied Districts. In Andhra Pradesh 13 hospitals have been short listed under JSY. Such accredited private hospitals have been certificated by the concerned District NRHM society. This certificate will mention the type of different services available and the level for which accreditation has been done. These accredited private institutions will go a yearly 
based scrutiny. However, the main allegation about such hospitals is that they are offering attractive incentives to the ASHA to bring JSY beneficiaries for delivery to the private hospitals. In majority cases these hospitals are not being reimbursed in time by the District NRHM society.

\section{Transport Arrangement}

Providing suitable and timely transport is a vital component of the JSY scheme. Basically local $\mathrm{PHCs} / \mathrm{CHCs} / \mathrm{ASHA}$ are need to arrange transport facility to the new mothers. Karnataka has launched 108 ambulance services and 'Nagu-Magu' scheme. These 108 ambulances help pregnant women to reach the hospital on time and will drop the new mother back to the home after delivery. This 108 ambulance service is being run by the Govt under the public private partnership with a mobile phone to the every driver. Here every ambulance driver will be trained in the first aid. Also these ambulances have been provided with the hi-tech medical emergency management facilities. In the interview, the District health officers have admitted the success of this scheme in Karnataka. Today this scheme has been executed in all PHCs/CHCs level. Normally ASHA (in Karnataka and Andra Pradesh) will organize transport service and she will be paid to this service. If the pregnant lady met this travel expenses this will be reimbursed at the time of discharge from the hospital after devilry. All CHCs/PHCs medical officers have been instructed to pay this incentive money to the women who used their own mode of transport to reach the hospital. Tamil Nadu and Andhra Pradesh have their own system to provide the transport facility to the pregnant women. Recently Andhra Pradesh has introduced a new scheme namely 102 exclusively to carry pregnant women to the hospital and back. This service is also available for ANC checkups too. In Andra pradesh and Tamil nadu at hobli or taluk level taxi drivers are giving paid transport services to the needy women. We feel ASHA and medical officers must be accountable for providing transport service.

\section{Payments to the Beneficiaries and ASHA:}

Payment of incentives to the beneficiaries and ASHA are very vital in the successes of this scheme. Hence, beneficiaries and ASHA were enquired about the time of payment details. As per the rule mothers' must be paid at the time of discharge from the hospital. We found timey payment' are being done in majority cases in all three states. However, in few cases delay in the payment can be seen in few districts because of inevitable situation. In the interview we found some major reasons for this issue including absence of the bank account, non availability of the grants, non submission of the required documents by the $\mathrm{PHC} / \mathrm{CHC}$ to the head office, early discharge of the beneficiaries, non-availability concerned signatories, unavailability of the cheque books etc. In the interview few medical officers' opined delay will also be happened because of use of non-registered vehicles to carry the pregnant women and the linking payment with the immunization of the new born. About the number of visits made by the mothers to receive cash incentives indicates that less than one-tenth had received the payment on the 'same day and slightly higher than one-fourth received the payment within one week as per this study. Efforts are also being done to introduce on line payment system for the new mothers. Few medical officers in Tamil Nadu and Andhra Pradesh added that shortage of cheque leaves is a key issue and linking payment to BCG immunization of the new born. We observed multiple agencies have been involved in the payment process like PRI/CHCs/PHCs/ASHA/ANM etc.

\section{IEC Activities for awareness creation}

IEC activities are the key tool to create more awareness about the scheme. Nodal officers and the medical officers of the PHCs/CHCs level were enquired about the IEC activities carrying out to generate demand for institutional deliveries in their jurisdictions. Efforts are being done about the scheme through news papers, hoardings, posters, wall paints, mass media etc. Also ASHA are doing door-to-door campaign spreading information above the scheme at the grass root level. Our discussions with the nodal officers and medical officers have revealed that they have developed a detailed awareness creation programme plan involving all the stake holders like nodal officers, ASHA, ANM etc. In Tamil Nadu special efforts are being done through the traditional media. Village health and sanitation committees and PRIs 
have also been involved in this process in all three states. However, medical officers admitted that role of PRIs are very limited here. In many PRIs, the VHSC committees are not properly functioning in Tamil Nadu and AP. Throughout the study we witnessed for the various IEC activities being implemented by the local PHCs/CHCs using folk medias'. Required funds are being released to the each district for carrying out this IEC activity. The level of IEC activities as the grass root level had been assessed as the base interview with the new mothers and other implementing agencies. In all three states electronic media is also being used as a part of IEC activity. In certain districts in Andra Pradesh IEC activities seems little bit low. In Karnataka community radio and community news papers are being used for IEC activities.

\section{Monitoring of JSY Scheme}

Monitoring is an integral part of the any scheme. Regarding the JSY scheme, majority nodal officers have opined monitoring is being done at two levels; first monthly reporting system. All the service unites are required to give the monthly report. In the later stage these reports will be consolidated at the suitable level. Reports from the SCs will be submitted to the PHCs and in turn reports from the PHCs will be submitted to the $\mathrm{CHCs}$ or to the district authorities for the scrutiny. Progress will be reviewed in the monthly meetings with the help of this report. The District level health officials and medical officers from all the concerned $\mathrm{PHCs} / \mathrm{CHCs}$ will participate in the meeting where monthly meetings of grassroots functionaries will be held on a routine basis to review the progress of various ongoing programmes. However, in some districts blocks have been divided into sectors for an effective monitoring system and the meetings will be held on the every third Friday in a month in Karnataka. Progress achieved will be matched with the targets for the month and suitable decisions will be taken in presence of the medical officers and the health workers. It was also pointed out by the nodal officers that a mandatory field visits and inspections by the state nodal offers is also a part of the monitoring system.

\section{FINANCIAL MANAGEMENT}

JSY is basically a conditional cash transfer benefit scheme. It is a $100 \%$ central government supported scheme and ministry of health and family welfare will channelize the fund to the all state health societies. Proper management of funds at all the levels will play a key role in the success of the programme. Each and every state in the country would have state NRHM society through which fund will be distributed to the district and the below (CHCs and PHCs). Depending on fund received by the centre the state nodal office will disburse the fund to the district health societies and this society will re-distribute the funds to the $\mathrm{CHCs}$ and PHCs in a particular district. This fund includes incentives for both the beneficiaries and the ASHA and to meet IEC activities and the programmes etc. For streamlining the financial management a National level budget will be prepared in the health Ministry, and then it will be sent to all the states. States are free to make any necessary changes in that budget. Each state is required to prepare its budget and the base of fund requirement and expected number of deliveries in a year. This will be prepared based on the estimations regularly submits by the CHCs, PHCs and SCs to the district office. Every district NRHM society will prepare a budget plan on the basis of the community survey. This survey gives a clear picture about the current situation and the future requirements. These requirements will be consolidated at the district level and all the districts will send their fund requirements to the state office. In turn the state converts these requirements into a demand and finally submits their demands to the central government to get fund under RCH programme.

Ministry has prepared a standard format to collect and to report the financial statement at all the levels back to its office. CHCs and PHCs need to submit the financial report to the concerned district office and the district office will consolidate the report and submit it to the state nodal office. Financial statement normally includes physical achievement, incentives, administration costs, programme management, hiring charges and overhead. 


\section{Receipt of Funds}

The receipting fund in this scheme is very vital. Some time fund flow will be regular and sometime this will be highly irregular. Tamil Nadu has received the first installment in the early part of the year in 201213 and 2013-14. But in case of Andhra Pradesh, JSY fund released sometime in August during the year 2013-14 and 2014-15. Karnataka had to gets the funds from other plans because of non-availability of JSY funds in 2014-15. However, the nodal officer has claimed that since 2016 onwards situation has much improved because of online payments. Irregularity in the receipt of the fund at the state level is a common phenomenon. In 2010-11 Andhra Pradesh had to go without JSY funds twice in a year. However, in 2015-16 none of the states have had faced any shortage of the funds. Some time all service providing agencies are receiving fund whenever it is required from the state office. In an extreme situation service providing agencies are empowered to use funds from the $\mathrm{RCH}$ flexi pool. This problem can be solved by having more reserved fund.

\section{Payment to the Beneficiaries and ASHA}

None of the states are being received the grants regularly. In these circumstances incentives are being issued to the beneficiaries and ASHA from the other plans. An irregularity in the fund flow management some time can be seen. Sometime states will receive the fund in the middle of the financial year. Because of this, the lower level service providing agencies are suffering a lot. In some instances states were allowed to use funds from the RCH flexi pool. However, during 2012-13 and 2014-15 all three states didn't have any problem in receiving the grants. Nonetheless, in case of 2015-16 they had some problem in receiving the grants. One time fund flow is a key issue in the success of the programme. It is expected that lower level service providing agencies must have some reserved fund for on time payment to the beneficiaries and ASHA workers.

\section{Fund Management due to Non-receipt of funds}

Since the funds will flow from the centre to the state we asked a specific question, how they would manage in case of shortage of money. Majority of the nodal officer admitted that the non-availability of the fund is a common issue and in such a situation they borrow funds from the other state plans. In certain circumstances, they are borrowing funds from the PRI or RCH flexi pool. In a worst situation nonpayment to the beneficiaries and ASHA workers could have been seen. Using funds from the different plans through the book adjustments creates a lot of confusions over tracking the account as opined by the few officials.

In majority cases diversion of the funds from the $\mathrm{RCH}$ programme is common. Because of this, $\mathrm{RCH}$ programme is moving away from its original priorities. All these issue are causing a lot of problem for intime payment to the beneficiaries. Some of the medical officers have admitted that statement of expenditure and utilization certificate sent by the PHCs and CHCs normally would have a lot of technical problems. Sometime the state office will make various queries to get the complete documentation before releasing any funds to the district. Some time reports submitted by the $\mathrm{CHCs}$ and PHCs would be incomplete and other required documents would be absent. Shortage of fund is a very common phenomenon in several times in a year. In such a situation state office some time diverts the funds from others schemes if not they need to wait for funds to come from the centre. Because of this, service providing agencies would not get their JSY budget. Hence, we can conclude that hampering of JSY services at the district level and the below is common because of non-availability of funds. Because of this reason, delay in the payment for the beneficiaries and the ASHA has become a very common phenomenon. Hence, it is advised to have more reserved funds in the early part of the year.

\section{Administrative cost}

In case of JSY programme the central government will release the grants to cover incentives for the beneficiaries, payment for ASHA and the administrative cost, expenditure of IEC activities etc to the states. Normally the state nodal office will use $1 \%$ of total cost as an administrative cost and the 
remaining $4 \%$ will be transferred to the district and the below as reported by the health officials. However, the nodal officer opined the administrative cost must be at least between $2 \%$ to $5 \%$. In Tamil Nadu it is found that the state will use $1-2 \%$ and the rest will be transferred to the district and the below. In Andhra Pradesh the proportion for the administrative cost varies from $1 \%$ to $4 \%$. In Karnataka sometime it varies from 2.5 to $5 \%$ Officials havr admitted that they are trying their best to keep administrative cost low and the same can be used for the IEC activities. However in some cases few district health officials didn't have any knowledge about the administrative cost.

\section{Reporting on Funds}

Normally each district will submit the monthly report on the physical achievement and expenditure to the state office regularly. We also found that sometime district authorities will not send the reports to the state office on time because of various reasons. In extreme situation, the state officials will get information over the phone. In some cases state/district finance officials will visit the respective institutes to get the clarifications. In some cases because of the technical problem in preparing statement of expenditure and utilization certificates $\mathrm{CHCs}$ and PHCs are facing delay in getting funds in time from the district/state level. In some districts in Tamil Nadu district health societies are getting professional advice from the qualified accountants. In Andhra Pradesh and Karnataka steps have been taken to improve the quality of the report with the consultants. All districts have been informed that financial reports must include needed supporting documents. However, this is not strictly being followed in any state.

\section{Problems in the financial report}

The District nodal officers have admitted that they are facing some problems in the financial report including the misinterpretation of opening balance, miscalculation about the cumulative expenditure, mismatch between number of the beneficiaries and incentives paid etc. It shows officials dealing with the account issue needs to be trained properly. Moreover, the district and the other lower implementing agencies are also facing the problems in handling advance grants. Since the district and other agencies are implementing various other health schemes along with JSY, officials opined it is some time quite difficult to track the fund flow. District offices are being regularly audited whereas no such auditing is taking place at PHCs or CHCs level. Because of huge number of beneficiaries some time it is not so easy to verify the genuinity of the beneficiaries as admitted by the ANMs/ASHA. It is also causing problems in handling the cash books, ledger books, cheque books etc. Using advance grants at the different levels are also causing some technical/auditing problems in the long run. In some districts the cheque books have been issued but not distributed. Further, differential payment to rural and urban beneficiaries is also causing a problem in tracking the fund flow. The District officials have admitted that the social auditing system and district ombudsman have been introduced to avoid mismanagement of funds. It is advised that periodic training for the account managers and monitoring of records needs to be done regularly. It is also advised to keep a separate account for JSY funds. So that book adjustment can be minimized.

\section{Barriers and bottlenecks in uptake of Institutional deliveries}

Since the beginning of the JSY scheme, various reports have proved that increasing numbers of the intuitional deliveries particularly in the Govt. health facilities across the three studied states. However, we have been observed a noteworthy quantity of people were either going for the private hospitals or opting delivery at home. Interview with the various stake holders found that socio-cultural and the poor economic background were some of the vital reasons for this. We had few focus group interviews with the new mothers and we found that distance factor, poverty, poor literacy level, gender discrimination, lack of awareness about the necessity and safety aspects of institutional deliveries, traditional beliefs were also some other factors why women would some time not go for institutional deliveries. For those living in far flung areas the distance of the facility is also a problem. Many nodal officers and MOs have also revealed that over the years, the number of ASHA have switched over to other jobs or left which has definitely affected the uptake of institutional deliveries. For instance, in one district in AP the nodal officer pointed out that number of ASHAs in his district had decreased by more than 10 percent with respect to number 
of ASHAs recruited. Even MOs and ANMs during the course of discussions had pointed out about vacant positions of ASHAs in their areas. Yet another factor that has been reported in some developed districts by the officials that agents of the Pvt. Nursing homes were paying handsome amount to ASHAs for diverting their cases to their hospitals. Some of the MOs were sincere enough to say that quality of services at the health facilities has to be improved significantly so as to attract people from educated and economically better off families.

\section{RECOMMENDATIONS}

\section{Policy Level}

At the outset, JSY programme has achieved a huge success in all three studied states viz. Karnataka, Tamil Nadu and Andhra Pradesh (Undivided). The study shows a big increase in institutional deliveries in all three states. It shows JSY has got a huge popularity. To handle this in-flux more capacity building measures to upgrade primary health centres and community health centre are needed and it should be $24 \times 7$ too.

It is suggested that effective participation of PRIs in JSY implementation is need of the hour. District NRHM societies or the health societies should ensure active engagement of PRIs, community and NGOs at different levels. It is felt that the proper guidelines are required for every level of PRIs for the effective implementation of JSY. It will also take cognizance of vital support to the PRIs are in farming village health plan, use of united funds etc. Regular orientation training for the PRI members and reading materials needs to be developed to facilitate their engagement at the different levels.

Some special drive is required to create the awareness about the significance of ANCs and PNCs, among the new mothers in rural parts than urban areas. There is a provision in the JSY guidelines to offer Rs.1500/- to a private doctor who is handling complicated deliveries in government hospitals. Till now, no money has been spent under this provision, because of absent of clear guidelines and the procedure to hire such private doctors.

Most of the PHCs and $\mathrm{CHCs}$ are running shortage of the manpower, infrastructure, laboratory service etc to handle large number of JSY cases. This issues needs to be properly managed soon. All the service implementing agencies should be provided with the enough reserved funds, cheque books etc. Enough reserved funds avoid diverting the funds from the other head/plan. To succeed in scaling down maternal and infant mortality, the community has an important role to play. The key stakeholders like PRI members, women SHG members, community opinion leaders, school teachers; the anganwadi needs to play a collective role.

This study has noticed low level participation of the private hospitals in this scheme. Private hospitals have good infrastructures and the state should utilize these facilities to cater the needs of JSY scheme. Different states have different guidelines with respect to the participation of the private hospitals leading some confusion. It should be avoided.

Community members demanded that the ANC and the PNC services should be available at the doorsteps through the mobile medical units and the doctors should be recruited especially lady doctors and to be made available for services as and when required. Better policy makers need to think in this way.

The inadequacy of equipments, drugs, and the infrastructure should be accessed through the facility surveys and the deficits are to be filled up urgently to meet increased demand of JSY beneficiary. For women living in the tribal and hilly districts, it becomes difficult to access $\mathrm{PHC} / \mathrm{CHCs}$ for infant/maternal care or delivery. A well-equipped sub-center is a better option for the normal delivery in this case.

If the mother or her husband, undergoes sterilization of their own, immediately after the delivery of the child, compensation money available under the existing scheme should be disbursed at the earliest. Orientation to community members on the formation and composition of VHSNC needs to be carried out at the GP level. Active SHGs, women groups, and other community based groups need to be involved in the process of formation. Emphasis needs to be given for ensuring full attendance and participation, besides design and contents, while planning and organizing training for VHSNC members. 


\section{Programme and Planning}

JSY plan should be prepared using the available utilization data. Also there must be an annual plan using the facility data. Focus should be given to the facility mapping along with the physical target achieved in the previous years. This kind of planning would help to identify the underserved areas. Also it helps to create facilities in these areas quickly. The state health plan for NRHM should reflect on the JSY interventions focusing planning and the financial demand. This will facilitate result based management. Every state has a nodal officer to take care the annual plans, budget, implementation, review and monitoring etc. These nodal offices' needs some reformations in the working style also.

Timely payment to JSY beneficiaries is necessary for sustaining interest in institutional delivery services. This study found that payments to beneficiaries are being delayed due to the various reasons. Actually payment should be made immediately after the delivery at the place of delivery. We also observed involvement of multiple agencies in giving payment which is causing confusions among the beneficiaries. There is a dearth need of reserved funds, Cheque books atleast with the district NRHM societies.

Timely availability of transport system is a key issue in this programme. A public private management based transport system should be effectively used. Also every service providing agencies should minimize 'over the counter drug' purchasing by the patients. The service norms of ASHA need to be revised. Each state is following its own norms and assigned responsibility with respect to ASHA service. In Karnataka and Tamil Nadu(TN) majority ASHA workers have completed only one level of training. In TN ASHA has been kept out of the JSY scheme. In majority cases they have not given books for the level 2,3 and 4 as reference materials and the training. The District NRHM society should have the responsibility of developing work plan for ASHA based on the guidelines given by the government of India.

There are no immediate supervisors like block facilitators for the ASHA workers in any district. Guidelines say for every 10 ASHA workers there should be one block facilitator. In few studied district block facilitator has been kept at minimal level after the training. We found a senior ASHA is monitoring the activities of other co ASHA workers. Monthly meeting with ASHA at PHC or CHC level is mandatory as per the guidelines. It is also given information about agenda to be discussed in this kind of meetings. This meeting should be chaired by the ANM. However, these meeting are not being held regularly and with the given agenda. Continuing education is a key segment to enhance the knowledge of ASHA workers. Absence of ASHA workers for meetings is very common in every state. It is suggested that required reading materials should be shared with ASHA during this type of monthly meetings.

We found that the ASHA workers are not being paid in time. This may lead to hamper the JSY programme severely in the long run. Also they are facing variety of problems including the poor service norms, harassments, heavy work load etc. Performance based reimbursement for the ASHA workers needs to be introduced. Moreover, they are being given less payment when compared to the other health workers. We also heard possible nexus between ASHA workers and the private hospitals about referring an economically beet off pregnant woman for delivery to the private hospitals. Private hospitals are giving an attractive amount to the ASHA workers to convince the pregnant woman regarding the place of delivery.

\section{Monitoring}

Monitoring at the different levels is a key success factor in the JSY programme. We found issues like differences in the payment, less payment, avoidable delays in payment, early discharge of the beneficiary, shortage of cheque leaves, absence of medical staff can be effectively addressed by the periodic visit by the nodal officers or introducing bio metric system. We also suggest an involvement of the district women and child development officers and PRIs in the monitoring activities. We suggest the state office should prepare a check list for the monitoring teams. They should also meet the JSY beneficiaries to get the feedback. It is also suggested to create JSY grievance cells in every service providing institutions. A helpline through NGO may be an option here. 


\section{Financial planning}

Absence of on time grant releasing mechanism is a key issue in this programme. Service providing agencies are not being given adequate advance grants. Hence money flow will be disturbed some time. Because of this problem in majority cases grants are being diverted from the other different sources to JSY programme. In an extreme condition, the medical officers should be given the power to use RKS fund or United fund. If required the service providing agencies must be given provision to hire needy additional human resources to handle payment issues by making use of the overhead charge available in the scheme. Additional human resource needed to streamline the financial management of the scheme in each district. Fund flow management in the JSY scheme can be effectively addressed by hiring the private experienced accountants.

\section{Demand generation}

Success of any programme depends on the publicity and communication strategies. Apart from the normal publicity strategies ASHA needs to visit door to door as a part of the campaign. Also certain district officials are using e- media, street play, wall painting and bill the board as a part of awareness creation. In some districts we noticed incomplete dissemination of messages also. We also found even key holders like, NGO, Anganawadi, SHG, PRI etc... don't have complete information about JSY scheme or functions of ASHA. District authorities are not focusing behavioral change communication plan to create more awareness about JSY programme. Also no efforts are being made to disseminate about the JSY programme during village health and nutrition day, health and sanitation committee meeting, health camps fairs etc. It is obvious that ASHA should be engaged at the optimum level in such activities. Normally rural people will have different health care behavior and misconceptions about institutional deliveries. Efforts required in this direction to remove such misconceptions. Health authorities can make use of folk media in this direction. District NRHM society must conduct regular orientation programmes for the different stake holders for an effective awareness creation programme about JSY.

\section{Conclusion}

JSY is not just about encouraging intuitional deliveries rather the major objective is rapid reduction of maternal and infant mortality in the country. Hence quality care in the service delivery is also an important issue in both pre and post partum care services. Hence it demands a quality care subject with respect to the human resources, laboratory services, labor rooms, wards and beds, drugs and other supplies, cleanliness, high quality services etc. In majority cases the service providing agencies may not stick to the evidence based guidelines. Hence, the health authorities must make sure maintaining the quality care at each and every level of JSY programme. The health society is not just to release funds but also must focus on the quality service delivery at every level. Private and public partnership system may be a good option in some more aspects here.

\section{Acknowledgment: Thanks to ICMR, New Delhi for the Grant support}

\section{References}

Jones, P., Hillierand Comfort, D. (2011). "Primary health care centers in the UK: putting policy into practice". Property Management, 27( 2):109-118.

Kumar and Hazra (2014) . "Impact Of Janani Suraksha YojanaOn Selected Family Health Behaviours In Rural India", Family Health Journal 56(1):12-15.

Mondal and others, (2017). "A Rapid Appraisal On Functioning Of Janani Suraksha Yojana In India”. National Institute Of Health And Family Welfare; 8(4):1-2

Mavalankar, D.(2009). "Primary Health Care under Panchayati Raj: Perceptions of Officials from Gujarat”. Asian Journal of Development Matters, 4(3):23-28 
Mutharayappa (2010), "Functioning Of Janani Suraksha Yojana Under National Rural Health Mission In Hassan District Of Karnataka", ISEC Report,23(3):23-25

Raghvan, K.,(2011). "An analysis of primary health care administration in Pune district". World Health Journal. 6(2):23-26.

Srinivasa(2001)."An analysis of primary health care administration in Karnataka”. Punjab University Journal.12(6):2428.

Sharma And Bhattacharya (2015). "An Assessment of Institutional Deliveries Under JSY In Jaipur District Rajasthan”. Indian J Public Health. 53(3):177-82.

Vanneman(2016) "Implementation Process of JSY In Rajastan" Health Issues. (45):56-66. 